\title{
Development of Rapid Detection Method for Volatilized Formaldehyde from Wood
}

\author{
Jung-Im Kim • Geun-Hyoung Choi • Oh-Kyung Kwon • Su-Myeong Hong • \\ Yun-Gi Park $\cdot$ Yong Sik Ok · Jin Hyo Kim
}

\section{목재 폼알데하이드 신속검출 공정개발}

김정임 · 최근형 · 권오경 · 홍수명 · 박연기 · 옥용식 · 김진효

Received: 1 November 2011 / Accepted: 26 December 2011 / Published Online: 31 March 2012

(C) The Korean Society for Applied Biological Chemistry 2012

\begin{abstract}
We designed a new rapid detection method for volatilized formaldehyde from wood. The process was installed with volatilizing and collecting parts in an incubator. For rapid sampling of formaldehyde from wood, we pulverized the wood to sawdust, and used 0.15-2.0 $\mathrm{mm}$ particles for the tests. The highest sampling rate $(94.8 \%)$ was obtained at $40 \mathrm{~mL} / \mathrm{min}$ flow rate and $100^{\circ} \mathrm{C}$. Under the optimized condition, we could collect the volatilized formaldehyde with good recovery rate. The developed method was applied to the monitoring of the formaldehyde from wood, and the measured concentrations were $0.7-4.6 \mu \mathrm{g} / \mathrm{g}$ from natural wood, 5.9-12.3 $\mu \mathrm{g} / \mathrm{g}$ from preserved wood, and 5.9$211.5 \mu \mathrm{g} / \mathrm{g}$ from chemical adhesive processed wood. From the results, we identified natural wood sawdust and chemically processed wood (medium density fiberboard, high density fiberboard, particle board) by the formaldehyde contents except preserved wood.
\end{abstract}

Keywords formaldehyde $\cdot$ rapid detection method $\cdot$ sawdust $\cdot$ wood

J.-I. Kim and G.-H. Choi contributed equally.

J.-I. Kim · G.-H. Choi · O.-K. Kwon · S.-M. Hong · Y.-G. Park · J. H. Kim ( $\varangle)$ Division of Chemical Safety, National Academy of Agricultural Science, RDA, Suwon 441-707, Republic of Korea

E-mail: setup75@korea.kr

Y. S. Ok

Department of Biological Environment, Chuncheon 200-701, Kangwon National University, Republic of Korea
서 론

퇴비는 토양비옥도 향상 및 작물생산성 유지를 위해 사용하는 대표적인 친환경 농자재이며, 축사에서 발생하는 폐분뇨의 대표 적인 재활용 제품이다. 이러한 퇴비 생산에는 폐분뇨와 함께 수 분 및 $\mathrm{C} / \mathrm{N}$ 비 조절을 위해 톱밥을 사용하고 있으며, 특히 퇴비 에서 톱밥이 차지하는 비중은 30-40\% 수준으로 매우 높은 편 이다. 이러한 퇴비 품질관리는 농촌진흥청 '비료 공정규격설정 및 지정'(농촌진흥청 고시 제2010-33호)에서 사용가능 소재 및 품질 등에 관하여 엄격히 규정하고 있으며, 목재패널제품에 대 하여 사용을 엄격히 금지하고 있다. 하지만, 톱밥 활용 증대에 따른 천연톱밥 가격상승으로 일부 업체에서 사용이 금지된 폐 목재(합판, medium density fiberboard (MDF) 등)를 퇴비용 톱 밥으로 사용하는 사례가 발생하고 있어 사회적 문제가 되고 있 다. 하지만, 톱밥 원료에 대한 화학적 가공 여부는 육안식별에 대부분 의존하고 있으며, 육안식별이 힘든 경우 총질소함량 분 석(Park 등, 1998; Chon 등, 2003) 및 폼알데하이드 분석(Lee 등, 2005)과 같은 고가의 분석장비와 긴 분석시간이 요구되는 시험법을 적용하고 있다. 따라서, 톱밥의 화학적 가공여부를 신 속히 판단할 수 있는 새로운 분석공정 및 분석기술개발이 요구 되고 있다.

현재까지의 전문 분석법들 중 총질소 함량분석은 멜라민수지 및 요소수지 등 질소원이 포함된 접착수지를 사용한 가공목재 에 대해서 적용 가능한 분석법으로, 화학적 가공목재 전반에 적 용할 수 없는 단점을 갖고 있다. 반면, 목재 패널제품에 사용되 는 접착제 중합물질인 폼알데하이드에 대한 분석은 다양한 가 공목재 판별에 활용 할 수 있는 장점을 갖고 있지만, 바이오 필 터기능이 우수한 목재에서 휘발성 물질인 폼알데하이드의 정량 적 포집 및 분석이 쉽지 않다.

목재 폼알데하이드는 대표적인 새집증후군 유발성 대기오염 물질로 알려져 있으며(Leena 등, 1992; Michael과 Douglas, 
1992), 이로 인해 건축용 혹은 가구용 목재는 방출기준 및 이 에 대한 공정시험법이 알려져 있다. 현재 고시된 공정시험법은 목재로부터 자연휘발량을 측정하는 데시케이터법과 챔버법(환경 부고시 제2004-80호, KSM-0000-2:2004, KSM-0000-4:2004) 이며, 이외에도 식품 용기 중 폼알데하이드 용출량 시험을 위 한 용매 용출법이 알려져 있다(Kawamura 등, 1995). 이들 분 석법은 최소 24 시간에서 최대 6개월가량의 포집기간이 요구되 고 있어, 목재의 화학적 가공성 여부를 신속하게 진단하지 못 하는 단점을 갖고 있다. 따라서 많은 연구자들이 폼알데하이드 포집시간을 단축하고자 챔버법을 수정한 Passive sampler에 대 한 연구를 진행하고 있지만(Kim 등, 2005), 여전히 포집시간 및 포집장치의 소형화 노력이 필요하다.

따라서, 본 연구에서는 현장에서 적용가능 하도록 분석법의 부피 및 시간을 줄인 신속검출 공정을 개발하고자 하였으며, 이 를 위해 챔버법을 변형한 폼알데하이드 신속 포집공정을 개발 하고, 목재의 화학적 가공 특성을 구분할 수 있는 지표를 도출 하고자 하였다.

\section{재료 및 방법}

분석대상 시료. 천연목재군은 건축/가구용으로 사용되는 소나무, 오동나무, 낙엽송, 사이프러스, 멀바우, 말라스, 헛개나무, 방킬 라이, 낙우송, 적삼목, 느티나무, 버드나무, 나왕, 백합나무, 갈 참나무, 화백나무 등 16 종을 사용하였으며, 화학적 가공목재군 은 MDF, high density fiberboard (HDF), particle board (PB), oriented strand board (OSB), 합판(plywood), 방부목을 시중에서 구매하였고, 전기톱을 이용한 기계적 분쇄 후 표준체 를 이용하여 걸러진 $0.15-2.0 \mathrm{~mm}$ 크기의 입자를 사용하였다.

목재수분함량 측정. 시험에 사용된 톱밥의 수분함량은 $120^{\circ} \mathrm{C}$ 로 유지되는 건조기 내에서 항량에 도달하는 시점까지 건조시킨 후 질량감소분을 측정하여 백분율로 계산하였다.

폼알데하이드 포집. 폼알데하이드 포집에 사용된 연결관 및 용 기는 모두 polytetrafluoroethylene (PTFE) 및 유리 재질을 사용 하였으며, 다음과 같은 방법으로 포집 하였다. 질소유량이 40 $\mathrm{mL} / \mathrm{min}$ 가 흐르도록 설계된 유리용기에 $5 \mathrm{~g}$ 의 톱밥을 삽입하고, $100^{\circ} \mathrm{C}$ 로 설정된 항온기에서 30 분간 휘발된 폼알데하이드를 $40 \mathrm{~mL}$ 의 증류수에 포집한다. 포집된 폼알데하이드는 아세틸아 세톤으로 유도체화 후 정량 분석하였다.

폼알데하이드 용매추출. 톱밥 $5 \mathrm{~g}$ 에 증류수 $50 \mathrm{~mL}$ 를 넣은 후 48시간 동안 교반추출 한다. 추출된 폼알데하이드는 $0.45 \mu \mathrm{m}$ 로 필터 한 뒤 아세틸아세톤으로 유도체화 후 정량 분석하였다.

아세틸아세톤 분석. 아세틸아세톤 시약은 아세트산암모늄 150 $\mathrm{g}$ 을 증류수 $800 \mathrm{~mL}$ 에 용해한 후 아세트산 $3 \mathrm{~mL}$ 와 아세틸아세 톤 $2 \mathrm{~mL}$ 를 잘 섞은 다음 $1000 \mathrm{~mL}$ 로 묽혀 조제하였으며, 폼알 데하이드 포집시료 $5 \mathrm{~mL}$ 에 아세틸아세톤시약 $5 \mathrm{~mL}$ 를 섞어, $60^{\circ} \mathrm{C}$ 에서 10 분간 반응 후 실온까지 냉각한 후 $412 \mathrm{~nm}$ 에서 흡 광도를 측정하여 정량분석 하였다.

\section{결과 및 고찰}

폼알데하이드 휘발량을 기준으로 목재특성을 구분하는 방법인 챔버법은 폼알데하이드 휘발 및 포집공정과 정량분석공정으로 구성되어 있다. 이러한 시험법에서 적용되는 휘발 및 포집공정 은 실온 및 대기압조건에서 최소 24시간 이상을 필요로 하며, 정량분석 공정은 포집된 폼알데하이드의 유도체화 후 크로마토 그래피 정량 혹은 비색정량 기술을 활용하고 있다. 특히 목재 시료 표면적은 단위시간당 폼알데하이드 휘발량에 큰 영향을 주 기 때문에, 휘발된 폼알데하이드량을 표준화 하기 위하여 단위 면적당 방산량 $\left(\mathrm{g} / \mathrm{m}^{2} \cdot \mathrm{h}\right)$ 으로 산출하고 있다. 따라서, 본 시험에 서는 폼알데하이드의 휘발 및 포집공정의 효율을 증대시키기 위 하여, 시료 표면적을 최대화하고자 하였으며, 이를 위해 $0.15-$ $2.0 \mathrm{~mm}$ 크기의 물리적으로 파쇄한 톱밥만 시험에 사용하였다. 사용된 톱밥의 종류별 입자크기 분포는 목재의 종류 및 가공특 성과 상관없이 전기톱으로 분쇄하였을 때 $0.15-0.5 \mathrm{~mm}$ 입자와 0.5-1.0 mm 입자 분포가 가장 많은 것으로 확인되었으며, 목재 별 입자크기 분포양상이 크게 다르지 않았다(Fig. 1).

목재 수분함량. 폼알데하이드는 수용성이 높은 휘발성 화합물로 서, 목재 수분함량에 따라 휘발량이 다를 수 있어, 시험에 사용 된 목재 수분함량을 측정하였다. 그 결과 시험에 사용된 사용 된 목재 중 합판 등 가공목재 수분함량은 $6.7-10.7 \%$ 범위에서

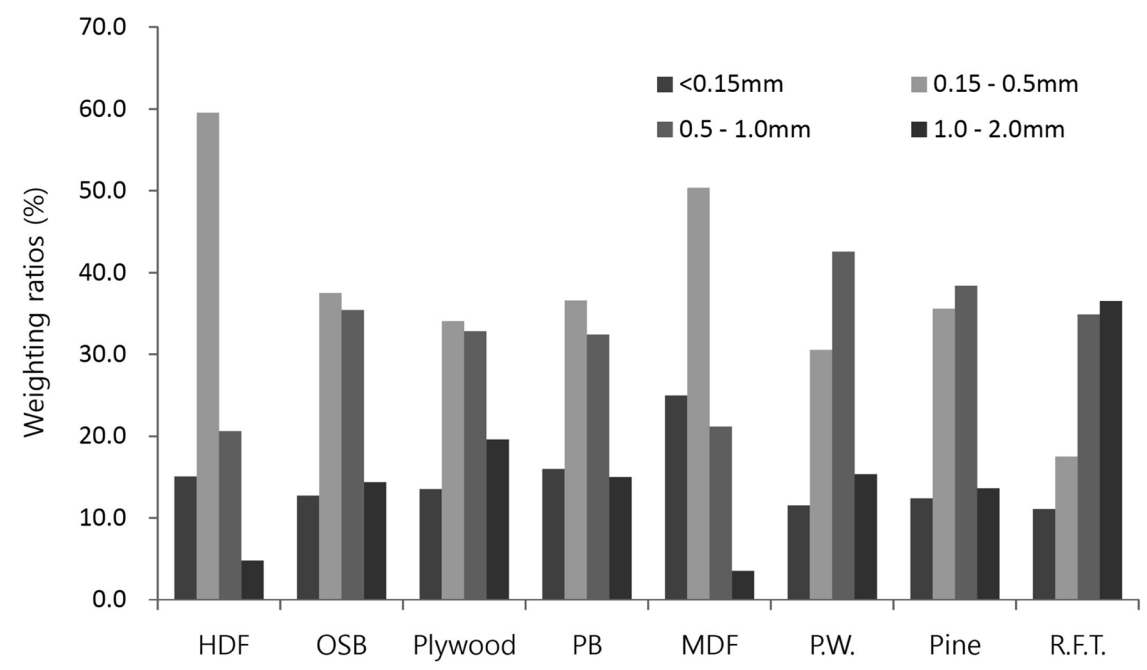

Fig. 1 The distribution ratio of particle size of the tested wood sawdust (P.W. and R.F.T. means preserved wood and royal foxglove tree, respectively). 


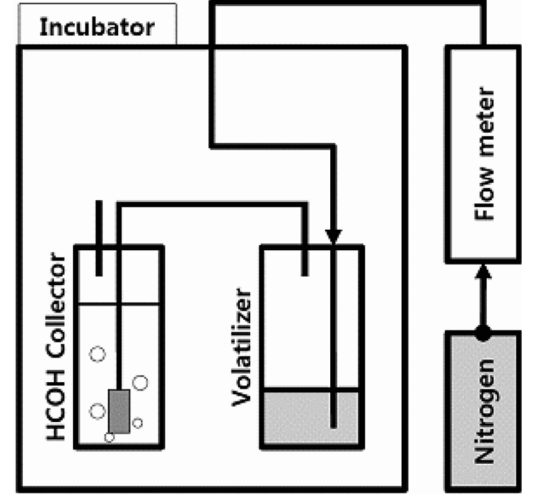

Fig. 2 A diagram of the volatilized formaldehyde collecting system.

측정되었으며, 천연목재는 4.70-28.0\% 수준으로 나타났다. 건축 용 및 가구용 목재는 일정기간 동안 건조과정을 거치기 때문에 목재 수분함량이 일정한 범위를 갖는 것으로 생각된다.

목재 폼알데하이드 포집 공정설계. 폼알데하이드의 물에 대한 높은 용해도 $(400 \mathrm{~g} / \mathrm{L} \mathrm{w} / \mathrm{w})$ 를 고려한다면, 톱밥 중 폼알데하이드 는 톱밥 수분에 용해되어 있을 가능성이 매우 높다. 이러한 수 용액 상태의 폼알데하이드를 원활히 휘발포집하기 위해서는 우 선 기체 증기압을 인위적으로 높여 줄 필요가 있다. 또한 톱밥 은 악취 및 각종 휘발성 유기오염물질 제거를 위한 바이오필터 로 잘 알려져 있어(Hong과 Park, 2007; Chen 등, 2008), 휘발 된 폼알데하이드가 톱밥에 재노출 될 경우, 톱밥으로 재포집 될 가능성이 매우 높아 재포집 억제 공정도 수반되어야 정량적 포 집이 가능할 것으로 판단하였다. 따라서, 목재 폼알데하이드 포 집에서 가장 긴 시간이 요구되는 휘발 및 포집공정을 신속하고 정확하게 진행하기 위하여 본 시험에서는 포집공정을 휘발부와 포집부로 나누어 설계하였다. 휘발부는 목재 폼알데하이드의 원 활한 휘발을 위하여 가온이 잘 되도록 열흡수율이 높은 밀폐된 갈색 유리용기를 사용하였으며, 휘발된 폼알데하이드의 포집부 이동은 질소기류를 이용하였다. 목재 폼알데하이드 포집을 위한 최적 온도 및 질소유량별 폼알데하이드 포집효율 산출을 위하 여 기준 포집시간을 30 분으로 설정하여 최적공정을 설계하였고, 요약한 모식도를 Fig. 2에 나타내었다.

포집률. 우선 본 연구에서 설계된 포집장치를 이용하여, 폼알데 하이드가 방출되지 않는 탈지면에 폼알데하이드 수용액을 투여 한 뒤, 휘발부 온도 및 질소유량별 폼알데하이드 포집률을 조 사한 결과 각 측정 온도별 최대 포집률은 $30^{\circ} \mathrm{C}$ 에서 $22.4 \%$, $60^{\circ} \mathrm{C}$ 에서 $61.6 \%$ 그리고 $100^{\circ} \mathrm{C}$ 에서 $94.8 \%$ 로 확인되었다. 이러 한 결과는 온도가 증가할수록 폼알데하이드 포집률이 향상되는 것으로 나타났으며, $60^{\circ} \mathrm{C}$ 이하의 온도 조건에서는 질소유량이 증가할수록 포집률이 다소 높아짐을 확인 할 수 있었다. 하지 만, 휘발부 온도 $100^{\circ} \mathrm{C}$ 에서 질소유량이 두 배씩 증가할수록 포 집률은 점차적으로 감소하는 경향을 나타내었다(Table 1). 이러 한 결과는 포집부에서 빠른 기체흐름으로 인해 충분한 포집효 과를 거두지 못하기 때문인 것으로 판단되어, 최적 질소기류량 을 $40 \mathrm{~mL} / \mathrm{min}$ 으로 설정하였다. 또한, 최적화된 조건의 정량적 포집능 확인을 위해 휘발부에 각각 $20,40,100,200 \mu \mathrm{g}$ 의 폼 알데하이드 수용액 $(100-2000 \mu \mathrm{g} / \mathrm{mL}, 0.1 \mathrm{~mL})$ 을 투입 뒤, 각 투 입량별 폼알데하이드 포집률을 측정한 결과 모든 시험범위에서 높은 포집률(81.1-114\%)과 폼알데하이드 투입량에 따른 포집량
Table 1 Collection efficiencies by flow rates and temperatures for formaldehyde in $\operatorname{cotton}^{\S}$

\begin{tabular}{cccc}
\hline \multirow{2}{*}{$\begin{array}{c}\text { Flow rate } \\
(\mathrm{mL} / \mathrm{min})\end{array}$} & \multicolumn{3}{c}{ Collection efficiency (\%) } \\
\cline { 2 - 4 } & $30^{\circ} \mathrm{C}$ & $60^{\circ} \mathrm{C}$ & $100^{\circ} \mathrm{C}$ \\
\hline 40 & $<5.0$ & $11.6 \pm 0.9$ & $94.8 \pm 5.0$ \\
80 & $6.7 \pm 2.9$ & $61.6 \pm 3.9$ & $89.8 \pm 0.5$ \\
160 & $22.4 \pm 0.3$ & $60.4 \pm 1.3$ & $75.5 \pm 7.9$ \\
\hline
\end{tabular}

$\S$ All the tests were performed with formaldehyde standard material (40 $\mu \mathrm{g})$ in cotton.

Table 2 The collection efficiencies at different amounts of formaldehyde in cotton ${ }^{\S}$

\begin{tabular}{cccc}
\hline \multirow{2}{*}{$\begin{array}{c}\text { Spiked } \\
\text { Formaldehyde } \\
(\mu \mathrm{g})\end{array}$} & \multicolumn{2}{c}{ Collected formaldehyde } & \\
\cline { 2 - 3 } & Amount (ig) & Rates (\%) & \\
\hline 20 & $16.23 \pm 0.642$ & $81.2 \pm 3.21$ & \\
40 & $45.52 \pm 0.382$ & $113.8 \pm 0.96$ & 0.9968 \\
100 & $99.95 \pm 4.280$ & $100.0 \pm 4.28$ & \\
200 & $192.11 \pm 5.004$ & $96.1 \pm 2.50$ & \\
\hline
\end{tabular}

${ }_{\S}$ All tests were performed under the optimized conditions (flow rate $40 \mathrm{~mL} / \mathrm{min}, 100^{\circ} \mathrm{C}$ )

의 정량적 상관관계 $\left(r^{2}=0.9968\right)$ 를 확인할 수 있었다(Table 2).

목재 중 폼알데하이드. 목재 중 폼알데하이드 포집은 톱밥 $5 \mathrm{~g}$ 을 시료로 사용하여 $100^{\circ} \mathrm{C}$ 에서 30 분간 질소기류하에서 증류수 에 포집된 양을 측정하였으며, 그 결과를 아래의 Table 3에 나 타내었다. 또한, 시험에 사용된 목재의 총 폼알데하이드량은 Kawamura 등(1995)이 사용한 용매추출법을 활용하여 측정하였 고, 그 결과 용매 추출을 통해 얻어진 목재 중 총 폼알데하이 드 함량과 본 시험에서 개발된 휘발량 측정법간의 정량적 상관 성 $\left(\mathrm{r}^{2}=0.8234\right)$ 이 확인되었다(Fig. 3$)$.

본 연구에서 개발된 공정을 톱밥에 적용한 결과, 소나무 등 16 종의 천연목재에서 검출된 폼알데하이드는 최저 $0.7 \mu \mathrm{g} / \mathrm{g}$ 에서 최대 $4.6 \mu \mathrm{g} / \mathrm{g}$ 으로 확인되었고, 오동나무의 폼알데하이드 평균 휘발량 $(4.4 \pm 0.36 \mu \mathrm{g} / \mathrm{g})$ 이 가장 높음을 확인 할 수 있었다. 화학 적 가공목재의 경우 접착제를 사용하지 않는 방부목이 가장 낮 은 폼알데하이드 휘발량 $(4.8 \pm 0.91 \mu \mathrm{g} / \mathrm{g})$ 이 확인되었으며, 접착제 를 사용하는 목재에서는 $\mathrm{OSB}$ 가 가장 낮은 휘발량 $(10.0 \pm 2.90 \mu \mathrm{g} /$ $\mathrm{g})$ 을 나타내었고, $\mathrm{HDF}(26.5 \pm 3.73 \mu \mathrm{g} / \mathrm{g}), \operatorname{MDF}(34.6 \pm 18.35 \mu \mathrm{g}$ / $\mathrm{g}), \mathrm{PB}(37.8 \pm 14.37 \mu \mathrm{g} / \mathrm{g})$, 합판 $(57.3 \pm 89.14 \mu \mathrm{g} / \mathrm{g})$ 순으로 확인 되었다(Table 3).

마지막으로, 본 시험법을 통해 화학적 가공목과 천연목의 구 분이 가능한지 확인하기 위하여, 본 시험에 사용된 목재를 3 개 의 집합군인 천연목재 집합군, 방부목 집합군(접착제를 사용하 지 않는 화학적 가공목군) 그리고, 마지막으로 접착제 가공목 집합군(접착제를 사용하는 $\mathrm{MDF}, \mathrm{HDF}, \mathrm{PB}$, 합판, $\mathrm{OSB}$ 를 집합) 으로 분류하였으며, 각 집합군별 폼알데하이드 휘발량을 Duncan's multiple range test (DMRT)를 통하여 분석하였다. 그 결과 폼알데하이드 평균 포집량은 천연목재군 $1.9 \pm 0.83 \mu \mathrm{g} / \mathrm{g}$ $(0.7-4.6 \mu \mathrm{g} / \mathrm{g})$, 방부목군 $4.8 \pm 0.91 \mu \mathrm{g} / \mathrm{g}(3.9-5.6 \mu \mathrm{g} / \mathrm{g})$, 접착제사 용 목재군 $35.3 \pm 39.56 \mu \mathrm{g} / \mathrm{g}(5.9-211.5 \mu \mathrm{g} / \mathrm{g})$ 으로 나타났다. 특 히 폼알데하이드 휘발량을 기준으로 천연목재군과 화학적 접착 제를 사용하지 않는 방부목군은 $95 \%$ 신뢰수준에서 유의차가 없 는 것으로 확인되었으나, 접착제 사용 목재 집합군과는 동일 신 
Table 3 Monitoring of volatilized formaldehyde from sawdust with the modified chamber method ${ }^{\S}$

\begin{tabular}{|c|c|c|c|}
\hline & & \multicolumn{2}{|c|}{$\begin{array}{l}\text { Formaldehyde in sawdust } \\
(\mu \mathrm{g} / \mathrm{g})\end{array}$} \\
\hline & & Range & Average \pm SD \\
\hline \multirow{16}{*}{$\begin{array}{l}\text { Natural } \\
\text { sawdust }\end{array}$} & Zelkova $(\mathrm{n}=3)$ & $0.7-0.7$ & $0.7 \pm 0.01$ \\
\hline & Sawara cypress $(n=3)$ & $0.7-0.8$ & $0.8 \pm 0.04$ \\
\hline & Malas $(n=3)$ & $1.1-1.2$ & $1.1 \pm 0.06$ \\
\hline & Merbau $(n=3)$ & $1.2-1.2$ & $1.2 \pm 0.01$ \\
\hline & Oriental raisin tree $(n=3)$ & $1.5-1.6$ & $1.5 \pm 0.03$ \\
\hline & Bangkirai $(n=3)$ & $1.6-1.8$ & $1.7 \pm 0.06$ \\
\hline & White oak $(n=3)$ & $1.6-1.9$ & $1.7 \pm 0.18$ \\
\hline & Pine $(n=11)$ & $1.1-2.7$ & $1.8 \pm 0.46$ \\
\hline & Western red cedar $(n=3)$ & $1.7-1.9$ & $1.8 \pm 0.14$ \\
\hline & $\operatorname{Larch}(n=6)$ & $1.3-2.4$ & $1.9 \pm 0.49$ \\
\hline & Bola cypress $(n=3)$ & $2.1-2.2$ & $2.1 \pm 0.06$ \\
\hline & Lauan $(n=3)$ & $2.1-2.7$ & $2.4 \pm 0.32$ \\
\hline & Willow $(n=3)$ & $2.5-2.8$ & $2.6 \pm 0.13$ \\
\hline & Cyprus(n=3) & $2.9-3.0$ & $2.9 \pm 0.05$ \\
\hline & liriodendron $(\mathrm{n}=3)$ & $3.1-3.2$ & $3.1 \pm 0.08$ \\
\hline & Royal foxglove tree $(n=3)$ & $4.0-4.6$ & $4.4 \pm 0.36$ \\
\hline \multirow{6}{*}{$\begin{array}{c}\text { Processed } \\
\text { wood sawdust }\end{array}$} & Preserved wood $(n=4)$ & $3.9-5.6$ & $4.8 \pm 0.91$ \\
\hline & OSB $(n=6)$ & $5.9-12.3$ & $10.0 \pm 2.90$ \\
\hline & $\operatorname{HDF}(n=6)$ & $21.4-30.7$ & $26.5 \pm 3.73$ \\
\hline & $\operatorname{MDF}(n=12)$ & $17.0-76.4$ & $34.6 \pm 18.35$ \\
\hline & PB $(n=14)$ & $17.9-59.3$ & $37.8 \pm 14.37$ \\
\hline & Plywood $(\mathrm{n}=8)$ & $6.2-211.5$ & $57.3 \pm 89.14$ \\
\hline
\end{tabular}

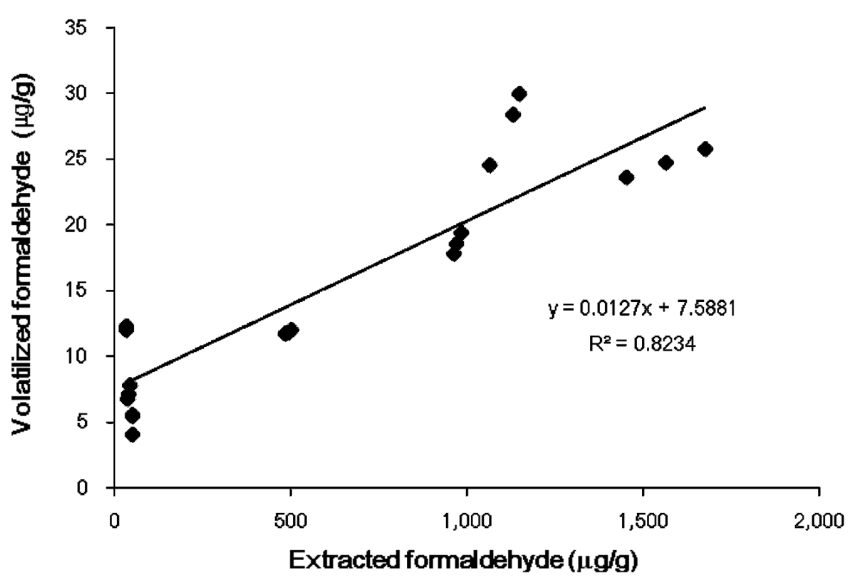

Fig. 3 Correlation of extracted and volatilized formaldehyde from sawdust.

뢰수준에서 유의차가 확인되었다. 따라서, 본 시험법에서 개발 된 목재 폼알데하이드 분석법은 접착제를 사용하는 가공목재와 천연목재를 구분해 낼 수 있는 것으로 확인하였다. 특히, 본 시 험법은 기존 챔버법과는 달리 장비를 소형화 할 수 있으며, 분 석시간을 1 시간 이내로 줄일 수 있어, 가공목재에 대한 간이분 석법으로 활용이 가능할 것으로 판단된다. 폼알데하이드 분석을 통해 구별하기 힘든 방부목은 목재가공시 첨가된 방부제 성분 인 구리 등에 대한 중금속 간이분석으로 판별 가능한 것으로 보고되어 있다(Abdelhafez 등, 2010). 또한, 본 연구에서 개발된
Table 4 Summary of volatilized formaldehyde from wood sawdust

\begin{tabular}{|c|c|c|c|}
\hline & & \multicolumn{2}{|c|}{$\begin{array}{l}\text { formaldehyde in sawdust } \\
\qquad(\mu \mathrm{g} / \mathrm{g})\end{array}$} \\
\hline & & range & average $\pm \mathrm{SD}^{\S}$ \\
\hline \multicolumn{2}{|c|}{ Natural sawdust ( $\mathrm{n}=59)$} & $0.7-4.6$ & $2.0 \pm 0.88 \mathrm{a}$ \\
\hline \multirow{2}{*}{$\begin{array}{l}\text { Processed } \\
\text { wood } \\
\text { sawdust }\end{array}$} & Preserved wood $(n=4)$ & $3.9-5.6$ & $4.8 \pm 0.91 \mathrm{a}$ \\
\hline & $\begin{array}{l}\text { All processed wood } \\
\text { except preserved wood }(n=46)\end{array}$ & $5.9-211.5$ & $35.3 \pm 39.56 b$ \\
\hline
\end{tabular}

${ }^{\S}$ Means followed by the letter are significantly different by DMRT's test at $p \leq 0.05$.

분석법은 목재시료 외에도 최근 문제가 되고 있는 사료 중 폼 알데하이드 첨가여부 판별에 적용가능한지 검토해 볼 필요가 있다.

\section{초 록}

본 연구에서는 목재로부터 신속한 폼알데하이드 정량분석 시험 법을 개발하고자 챔버법을 변형한 방법을 설계하였으며, 톱밥시 료는 0.15-2.0 mm 크기의 입자를 사용하였고, 휘발부와 포집부 가 분리된 장치에서 휘발온도 및 질소유량별 폼알데하이드 포 집률을 측정하였다. 그 결과 질소유량 $40 \mathrm{~mL} / \mathrm{min}, 100^{\circ} \mathrm{C}$ 조건 에서 30 분간 포집 할 경우 $94.8 \%$ 의 최대 포집률이 확인되었으 며, 본 공정의 농도별 폼알데하이드 포집률은 $71.0-94.8 \%\left(\mathrm{r}^{2}=\right.$ 0.9968 로 확인되었으며, 목재 중 총 폼알데하이드 농도가 증가 할수록 휘발된 폼알데하이드량이 정량적으로 증가함을 확인할 수 있었다 $\left(r^{2}=0.8234\right)$. 목재종류 별 폼알데하이드 평균 함량은 천연톱밥 $(0.7-4.6 \mu \mathrm{g} / \mathrm{g})$, 방부목 $(3.9-5.6 \mu \mathrm{g} / \mathrm{g})$, 접착제 사용 가공 목재 $(5.9-211.5 \mu \mathrm{g} / \mathrm{g})$ 순으로 낮은 함량을 확인하였고, 각 그룹 별 폼알데하이드 분석결과에 대한 Duncan's multiple range test 수행결과 천연톱밥과 접착제를 사용하지 않는 방부목은 $95 \%$ 신 뢰수준에서 유의적 차이를 나타내지 않았으나, 천연톱밥과 접착 제 사용목재간에는 동일 수준에서 유의차가 확인되었다. 이러한 결과로 볼 때, 접착제가 사용된 목재는 본 시험분석을 통해 신 속하게 천연목재와 구분이 가능 할 것으로 판단된다.

Keywords: formaldehyde, rapid detection method, sawdust, wood

감사의 글. 본 연구는 농촌진흥청 국립농업과학원 시험연구 사업비(PJ008468) 로 수행되었습니다.

\section{참고문헌}

Abdelhafez AA, Awad YM, Abd El-Azeem SAM, Kim M-S, Ham K-J, Lim K-J, Yang J-E, and Ok Y-S (2010) Leaching of chromium, copper and arsenic in soils and rapid identification of CCA-treated woods using modified PAN stain. Korean J Soil Sci Fert 43, 60-67.

Chen L, Hoff SJ, Koziel JA, Cal LS, Zelle B, and Sun G (2008) Performance evaluation of a wood-chip based biofilter using solid-phase microextraction and gas chromatography-mass spectroscopy-olfactometry. Biores Technol 99, 7767-7780.

Chon SS, An L, Kim YK, Ju CS, Kwon EM, Jin CS, and Jung WJ (2003) Study on the effects of selected microorganisms to accelerate the cocomposting of food waste and sewage sludge. Korean Soc Environ 
Engineers 5, 1398-1402.

Hong JH and Park KJ (2007) Performance characteristics of agitated bed manure composting and ammonia removal from composting using sawdust biofiltration system. J Livestock Housing \& Environ 13, 13-20.

Kawamura Y, Funakoshi K, Sugita T, and Yamada T (1995) Residues of formaldehyde in woodenware. J Food Hyg Soc Jpn 36, 731-737.

Kim ST, Yim BB, and Jeong JH (2005) Development of a passive sampler using 4-amino-3-hydrazino-5-mercapto-1,2,4-triazole for measuring indoor formaldehyde. J Korean Soc Atmos Environ 21, 593-603.

Lee SJ, Jang SK, Kim MH, Lee HS, Lim JH, Jang M, and Seo SY (2005) Evaluation of sampling and analytical method for emission experiment of pollutants in building materials using small chamber. Anal Sci \& Tech 18, 344-354.

Leena M, Jouni J, and Olli S (1992) The effect of air humidification on symptoms and perception of indoor air quality in office. Arch Environ Health 47, 8-15.

Michael D and Douglas S (1992) Indoor Air 90': Health effects associated with indoor air contaminants. Arch Environ Health 47, 6-7.

Park JB, Kim YS, Han SH, Song SY, and Choi SS (1998) The characterization of physico-chemical properties on the composting of municipal organic wastes. KORRA 10, 75-85. 